\title{
Diastematomyelia differences in management of diastemetomyelia with associated abnormalities versus isolated diastemetomyelia: a case series
}

\author{
Salini Raani J. P. ${ }^{1}$, Ashwin Rao ${ }^{1 *}$, Madhan Balu ${ }^{2}$, Rashmi Rao ${ }^{1}$
}

\begin{abstract}
${ }^{1}$ Department of Obstetrics and Gynaecology, Salem Polyclinic, Salem, Tamil Nadu, India
${ }^{2}$ Department of Paediatrics, Salem Polyclinic, Salem, Tamil Nadu, India
\end{abstract}

Received: 27 August 2020

Accepted: 01 October 2020

\author{
*Correspondence: \\ Dr. Ashwin Rao, \\ E-mail: ashwinrao2404@gmail.com
}

Copyright: (c) the author(s), publisher and licensee Medip Academy. This is an open-access article distributed under the terms of the Creative Commons Attribution Non-Commercial License, which permits unrestricted non-commercial use, distribution, and reproduction in any medium, provided the original work is properly cited.

\begin{abstract}
Diastematomyelia (DM), also known as split cord malformation (SCM) is a type of spinal dysraphism. It is a very rare congenital spinal anomaly characterized by clefting of the spinal cord due to a partial or complete bony or fibrous septum within the spinal canal with splaying of the posterior spinal elements resulting in localized division of the spinal cord into two parts on either side of the septum which typically reunite below the cleft. The pathology was first described by Cruvelhier in 1853. About 1-3 per 1000 live birth, is the estimated incidence of spinal dysraphism and neural tube defects (NTD) occurs more commonly in females (55-70\%). Prenatal diagnosis of DM is possible by ultrasonography (USG). The clinical significance of DM is that it may manifest as an isolated abnormality or in association with other spinal abnormalities such as spina bifida, Arnold-Chiari malformation, hemivertebra, butterfly vertebra, kyphoscoliosis or part of Jarcho-Levin syndrome. The management of pregnancy with a foetus diagnosed with DM antenatally, differs based on whether the foetus has an isolated DM with intact skin or DM with more serious associated anomalies. We present two cases of Foetal DM both diagnosed by antenatal USG, Case 1 was diagnosed at 16 weeks gestation age (GA) with DM associated with Type II Arnold-Chiari malformation, hydrocephalus and case 2 was diagnosed with isolated DM at 19 weeks 2 days GA.
\end{abstract}

Keywords: DM, Spinal dysraphism, Laminectomy, NTD

\section{INTRODUCTION}

DM also known as SCM is a type of spinal dysraphism. It is a very rare congenital spinal anomaly characterized by clefting of the spinal cord due to a partial or complete bony or fibrous septum within the spinal canal with splaying of the posterior spinal elements which results in localized division of the spinal cord. The two parts on either side of the septum i.e., the two hemi cords typically reunite below the cleft with the conus lying in an abnormally low position. The cleft is most commonly located $(70-80 \%)$ at the upper lumbar or lower thoracic regions, but it manifests at any level of the spinal cord. ${ }^{1}$ The pathology was first described by Cruvelhier in $1853 .^{2}$
Two types of DM have been defined: type 1 is characterised by each hemi cord having its own dural sheath, and type 2 is characterised by both hemi cords covered by a common dural sheath. About 1-3 per 1000 live birth is the estimated incidence of spinal dysraphism and NTD. It occurs more commonly in females (55$70 \%){ }^{3}$ The clinical significance of DM is that it may manifest as an isolated abnormality or in association with other spinal abnormalities such as spina bifida, ArnoldChiari malformation, hemivertebra, butterfly vertebra, or kyphoscoliosis and also can be seen as part of JarchoLevin syndrome. Prenatal diagnosis of DM is possible by USG. Amniotic fluid acetylcholine esterase (AF-AChE) levels and foetal magnetic resonance imaging (MRI) can be helpful to rule out additional anomalies. ${ }^{4}$ 


\section{CASE 1}

A 26-year-old woman, gravida 2, para 1, live 1 was examined at about 16 weeks of gestation. She had not taken any folic acid supplements during the period of embryogenesis for her present pregnancy. She had previously delivered a live female child vaginally at term weighing $3000 \mathrm{gm}$ who has normal growth and development. Initial USG of her $2^{\text {nd }}$ pregnancy at another institution was considered abnormal at 14 weeks 6 days, revealing an echogenic focus seen in the mid-line of the foetal spine and dilated ventricles of foetal brain. For further evaluation the patient was referred to our place. Her follow-up USG at 16 weeks revealed an abnormal widening of the posterior ossification centre in the lumbar region of foetal spine with a central bright linear echo within the canal (Figure 1) and enlargement of foetal lateral ventricles of the brain showing hydrocephalus and a typical lemon sign of foetal skull (Figure 2); pointing to the diagnosis of DM with type II Arnold-Chiari malformation. A lipoma within the dysraphic canal was unlikely to produce a well-defined echo. The family was counselled about the anomaly of the foetus and they decided to abort the foetus. The women had medical termination of pregnancy (MTP) and expelled a dead male foetus weighing $150 \mathrm{gm}$. Post-mortem study was not performed. The abortus had intact skin and no open neural tube defects were visible, thus excluding the diagnosis of meningocele and myelomeningocele.

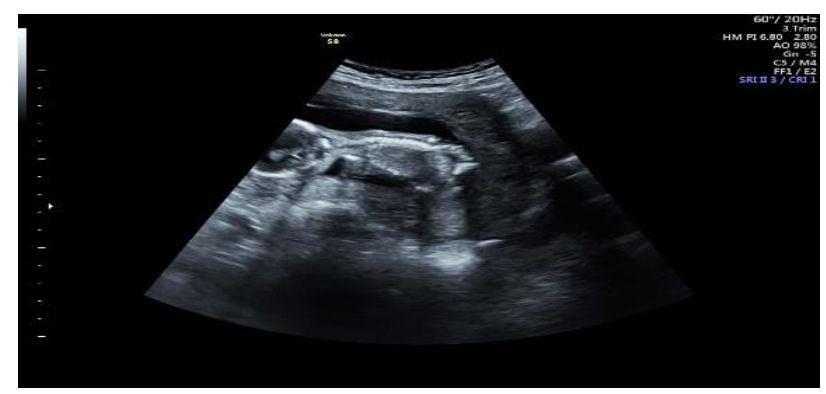

Figure 1: Antenatal USG of DM (case 1).

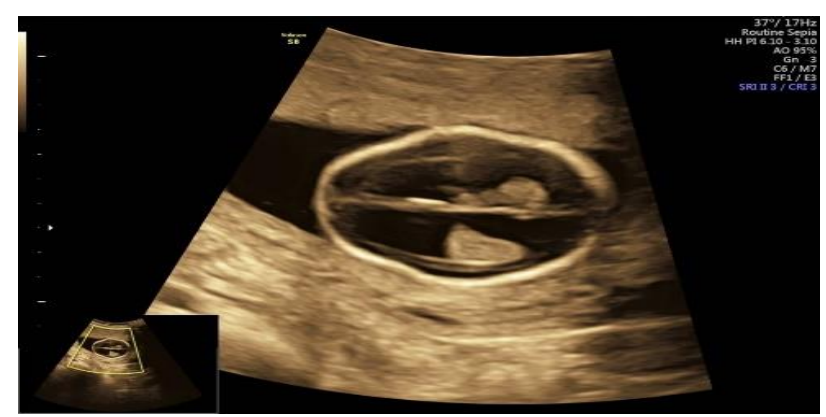

Figure 2: Lemon sign of foetal skull of Arnold-Chiari type II malformation (case 1).

\section{CASE 2}

A 25-year-old women, gravida 3, para 2, live 0 at 11 weeks 4 days of amenorrhea came to the institution for confirmation of pregnancy. The couple had a $2^{\text {nd }}$ degree consanguineous marriage. She had a family history of consanguineous marriage for 3 generations ( $2^{\text {nd }}$ degree), delayed pregnancies and congenital limb deformities in the family. In her first pregnancy, she delivered a female child at term by caesarean section (LSCS) weighing 2000 gm, who died at day 2 of life. In her second pregnancy at 29 weeks 2 days of gestation she presented to the institution with decreased foetal movements, which on USG showed intra-uterine demise of the foetus. The following LSCS delivered a dead female child with cord twice around the neck weighing $1500 \mathrm{gm}$. She had genetic counselling prior to her present pregnancy. Carrier mutation screening was recommended to the couple. She was advised to take prophylactic folic acid and vitamin B12 supplements, 3 months prior to conception. At her present pregnancy, at 11 weeks 4 days, nuchal translucency (NT) scan and biochemical test for PAPP-F and beta-HCG was performed and her $1^{\text {st }}$ trimester screening showed low risk for NTD. Her follow up USG at 16 weeks 1 day, didn't detect any NTD. But her anomaly scan at 19 weeks 2 days, revealed DM with a bony spur at the level of the lumbar spine (Figure 3) without any other associated abnormality. The family was counselled about the anomaly of the baby, but they wanted to continue the pregnancy. Her follow up USG at 22 weeks 2 days, 31 weeks 1 day and 36 weeks 1 day revealed biometry parameters appropriate for GA and isolated DM of foetal spine with no other associated anomalies. The present pregnancy was terminated by an elective LSCS at 38 weeks 4 days GA, delivering a live male baby, weighing 3060 gm (Figure 4). On Day 2 of life, post-natal USG revealed localized splitting of the spinal cord into two at L4-L5 region which fuses as one cord above and below the lesion (Figure 5), thus confirming DM of spinal cord. A spine X-ray of the neonate revealed congenital scoliosis and a butterfly vertebra of T4 (Figure 6). The paediatrician discussed with the couple about the imaging reports and recommended monthly out-patient visit to detect any neurological signs of deterioration. The need for an MRI at around 3 months of age to confirm the diagnosis of DM following which the infant might need surgical correction by prophylactic laminoplasty, as early surgical intervention prior to development of permanent neurological deficits has a better prognosis.

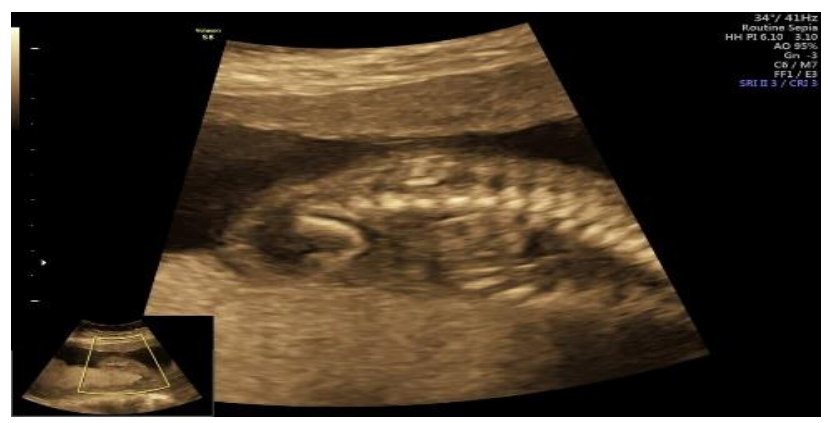

Figure 3: Antenatal USG of DM (case 2). 


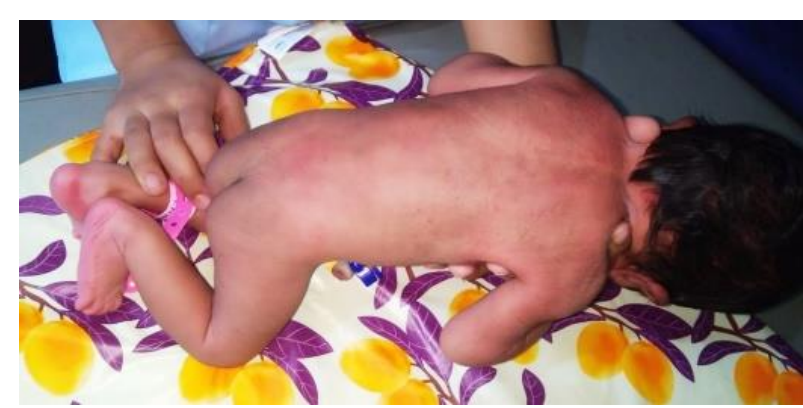

Figure 4: No external signs of NTD (case 2).

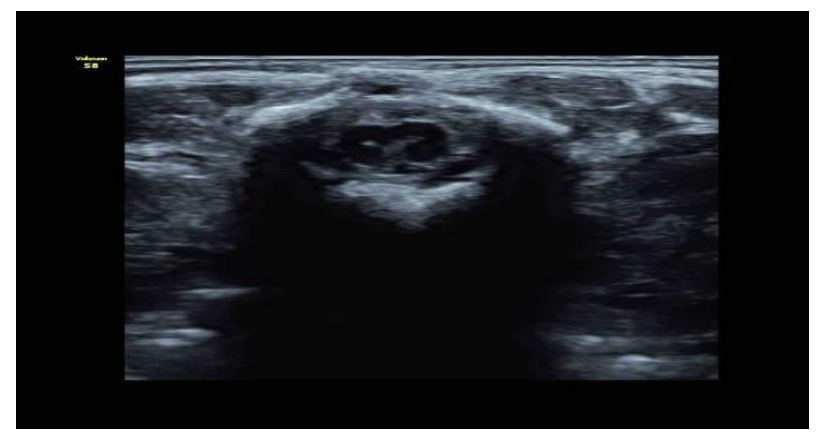

Figure 5: Post-natal USG of foetal spine of DM (case 2).

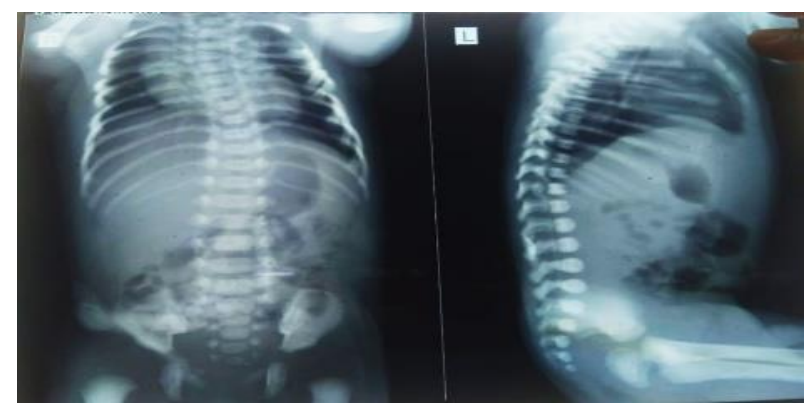

Figure 6: Post-natal X-ray of foetal spine shows of congenital scoliosis and a butterfly vertebra of $\mathrm{T} 4$ (case 2).

\section{DISCUSSION}

DM or SCM is an uncommon congenital spinal cord anomaly which results in longitudinal clefting of the spinal cord into two hemi cords. The two hemi cords usually separated by an osseous, fibrous or cartilaginous septum and dwell in two independent dural tubes (type I DM). In type II DM both hemi cord are enclosed within a solitary, dural tube which is not duplicated. Each hemi cord typically has one ventral horn, a central canal and one dorsal horn, which mostly re-join caudally. ${ }^{5}$ Approximately $1 / 3^{\text {rd }}$ of patients with DM have associated spinal dysraphisms. DM is thought to occur due to a defect occurring during $3^{\text {rd }}$ and $4^{\text {th }}$ week of gestation and prior to neural tube closure. Pang initially described the pathogenesis of spinal dysraphisms stating that there is the presence of a conduit (accessory neurenteric canal) communicating between the amniotic sac and yolk sac during gastrulation which allows for endoderm to move up into the midline tract and divide the neural plate and proto-notochord in halves. Around this a cluster of other primitive architectural stem cells group form ultimately develop into features of a mature DM. ${ }^{2}$ Later, he postulated that the accessory neurenteric canal could be formed by a localized square-pulse type unsuccessful integration of the merging proto-notochordal cells which arise from either side of Hensen's node's dorsal lips. These intrude between the contiguous ectodermalendodermal plates prior attaching with the lengthening rear of the median plane of the notochord forming two hemi-notochords thereby each inducing the neural plate above to form two-hemi cords giving rise to features eponymic to DM. The endoderm and ectoderm plates between the hemi cords remain and the primitive cells of all three embryonic germ layers form structures like bone spurs, cartilage, fat, dermoid cysts, etc. USG helps to diagnose DM in the antenatal and postnatal period. On USG, DM presents as an echogenic structure extending from the posterior elements to the posterior aspect of a vertebral body and widening of spinal canal in coronal plane may be seen. ${ }^{6}$ Prior to radiological advancements like MRI, myelography and post myelogram CT, plain radiographs were used. Plain radiography poorly estimates DM, but it helps to detect associated vertebral segmental anomalies like congenital scoliosis which occurs in $79 \%$ of cases. Myelography escalates the accuracy of assessment but is an invasive investigation. CT reveals the structure and type of the spur, i.e. whether the spur is bony, cartilaginous or fibrous in nature and it best shows the bony spur and vertebral defect. MRI delineates the existence and the extent of spinal cord division. ${ }^{7}$ The surgical treatment of both type I and type II DMs is about eliminating the bony or cartilaginous spurs which lead to spinal cord tethering thus causing progressive neurological deterioration. ${ }^{2}$ Shaw reported that 7 out of 8 patients with DM developed a progressive neurological deficit during growth which was initially absent. ${ }^{8}$ This was an indication for surgery but there was only limited clinical improvement following surgery once the neurological deficits sets in. Thus, as soon as any neurological deterioration signs are detected, a prophylactic laminoplasty over laminectomy is preferred for better prognosis of the infant. ${ }^{9}$ Cases which show no signs of neurological deterioration, should be meticulously observed and managed surgically if any signs of deficit occur.

\section{CONCLUSION}

DM, although a rare congenital deformity of the spinal cord can be detected by antenatal USG. Amniotic fluid acetylcholine esterase (AF-AChE) levels and foetal MRI can be helpful to rule out additional anomalies. The diagnosis of DM is crucial as pregnancy can be continued if DM exists as an isolated entity but needs termination if DM is associated with other serious anomalies. Patients with isolated DM would require prophylactic surgical intervention as soon as any neurological deterioration 
signs appear but patients with no signs of deterioration need meticulous observation and managed surgically if any signs of deficit occur.

Funding: No funding sources

Conflict of interest: None declared

Ethical approval: Not required

\section{REFERENCES}

1. Caspi B, Gorbacz S, Appelman Z, Elchalal U. Antenatal Diagnosis of Diastematomyelia. J Clin Ultrasound. 1990;18:721-5.

2. Pang D. Perspectives on Spinal Dysraphism: Past, Present, and Future. J Korean Neurosurg Soc. 2020;63(3):366-72.

3. Kumari MV, Supriya P, Aemjal SC, Raghavendra V. Role of MRI in evaluation of suspected spinal dysraphism. J Evolution Med Dent Sci. 2016;5(17):879-84.

4. Kutuk MS, Ozgun MT, Tas M, Poyrazoglu HG, Yikilmaz A. Prenatal diagnosis of split cord malformation by ultrasound and foetal magnetic resonance imaging: case report and review of the literature. Childs Nerv Syst. 2012;28(12):2169-72.
5. Bekki H, Morishita Y, Kawano O, Shiba K, Iwamoto Y. Diastematomyelia: A surgical case with long-term follow-up. Asian Spine J. 2015;9:99-102.

6. Upasani VV, Ketwaroo PD, Estroff JA, Warf BC, Emans JB, Glotzbecker MP. Prenatal diagnosis and assessment of congenital spinal anomalies: Review for prenatal counseling. World J Orthop. 2016;7(7):406-17.

7. Huang S, He X, Xiang L, Yuan GL, Ning N, Lan BS. CT and MRI features of patients with diastematomyelia. Spinal Cord. 2014;52(9):689-92.

8. Shaw JF. Diastematomyelia. Dev Med Child Neurol. 1975;17:361-4.

9. Vissarionov SV, Krutelev NA, Snischuk VP, Alam M, Kravchenko AP, Zheng YP et al. Diagnosis and treatment of diastematomyelia in children: a perspective cohort study. Spinal Cord Ser Cases. 2018;4:109.

Cite this article as: Salini RJP, Rao A, Balu M, Rao R. Diastematomyelia differences in management of diastemetomyelia with associated abnormalities versus isolated diastemetomyelia: a case series. Int $\mathbf{J}$ Reprod Contracept Obstet Gynecol 2020;9:4688-91. 